Esta revista forma parte del acervo de la Biblioteca Jurídica Virtual del Instituto de Investigaciones Jurídicas de la UNAM

\title{
EL ACCESO A LA INFORMACIÓN PÚBLICA EN ACTOS ADMINISTRATIVOS DE CARÁCTER GENERAL CARACTERIZADOS POR SU PUBLICIDAD. CASO "NOM-046-SSA2-2005. VIOLENCIA FAMILIAR, SEXUAL Y CONTRA LAS MUJERES. CRITERIOS PARA LA PREVENCIÓN Y ATENCIÓN"
}

\section{Cristian Miguel ACOSTA GARCíA*}

\section{INTRODUCCIÓN}

Las normas oficiales mexicanas son actos administrativos de carácter general cuya particularidad radica en que, para su creación o modificación, debe realizarse una consulta pública que garantiza la transparencia, la publicidad y la legitimidad de la regulación generada. La modificación a la "NOM-046SSA2-2005. Violencia familiar, sexual y contra las mujeres. Criterios para la prevención y atención”, publicada en el Diario Oficial de la Federación el 24 de marzo de 2016, no respetó dichos principios y justificó una modificación trascedente en una mera "homologación".

Al solicitar, mediante la plataforma de transparencia, los expedientes generados con motivo del proceso de modificación de dicha norma, la Secretaría de Salud clasificó la información como reservada, fundando su actuación en términos del artículo 113, fracción XI, de la Ley General de Transparencia y Acceso a la Información Pública (en adelante LGTAIP), con su correlativo 110, fracción XI, de la Ley Federal de Transparencia y Acceso a la Información Pública (en adelante LFTAIP), al considerar que se vulnera la conducción de expedientes judiciales que no han causado estado, pues en contra de dicha norma existen tres controversias constitu-

* Maestro en derecho por la Facultad de Derecho de la UNAM, y profesor en la Facultad de Estudios Superiores Acatlán de la misma Universidad, cmiguel.ac@gmail.com.

Fecha de recepción: 13 de julio de 2018.

Fecha de dictamen: 22 de agosto de 2018. 
Esta revista forma parte del acervo de la Biblioteca Jurídica Virtual del Instituto de Investigaciones Jurídicas de la UNAM

cionales pendientes de resolución por la Suprema Corte de Justicia de la Nación (SCJN).

Lo anterior ha permitido al Instituto Nacional de Acceso a la Información Pública y Protección de Datos Personales (en adelante INAI) generar una labor interpretativa relevante sobre la clasificación de los procesos de modificación de normas oficiales mexicanas caracterizadas por su publicidad y transparencia.

\section{ONTOlogía DE LAS NORMAS OFICIALES MEXICANAS}

El estudio sistemático de las normas oficiales mexicanas, así como de los principios de publicidad, transparencia y consulta pública que las rige, debe realizarse atendiendo al género próximo de dichas normas y las diferencias específicas existentes entre conceptos no ostensibles; por tal motivo, es pertinente atender la regla ciceroniana (Cicerón, 2007), retomada de Aristóteles (Analíticos primeros, 1988), para establecer el significado de los conceptos: acto administrativo, actos administrativos de carácter general y normas oficiales mexicanas.

De esta manera, el significante "acto administrativo" tiene su género próximo en el diverso concepto de "acto jurídico" (propio del derecho privado), y es posible hablar del primero sin referir previamente al segundo. El significante "acto" proviene del latín actus, -us, y éste, a su vez, es derivado del verbo ago-is-ere-egi-actum, que se conceptualiza como un hecho voluntario que crea, modifica o extingue relaciones de derecho (en francés, acte, en italiano atto, en inglés, act y en alemán Handlung) (Dahesa, 2006), que a la luz del significante de acto jurídico refiere a una manifestación exterior de voluntad que se hace con el fin de crear, transmitir, modificar o extinguir derechos y obligaciones.

Ahora bien, el concepto no ostensible de "acto administrativo", desde la dogmática jurídica, resulta equívoco y polisémico, por lo que se han creado diversos conceptos sobre el mismo atendiendo a las características del emisor, a la distinción entre actos formales y materiales, a la voluntad o no del mismo, o a su unilateralidad y/o bilateralidad, entre otros. Para efectos de este comentario, se suscribe la definición del ministro Pérez Dayán, quien lo define como una declaración de voluntad unilateral y concreta dictada por un órgano de la administración pública en ejercicio de su competencia administrativa, cuyos efectos jurídicos son directos e inmediatos (Pérez, 2014). Dicha definición cobra relevancia al considerar que la expo- 
Esta revista forma parte del acervo de la Biblioteca Jurídica Virtual del Instituto de Investigaciones Jurídicas de la UNAM

sición de motivos de la Ley Federal de Procedimiento Administrativo (en adelante LFPA) acota al acto como "la forma como se expresa la voluntad del Estado en su función administrativa para aplicar y concretar la ley a casos particulares", y distingue entre actos administrativos individualizados y actos administrativos de carácter general.

Así, el artículo 4o. de la LFPA establece que los actos administrativos de carácter general pueden ser reglamentos, decretos, acuerdos, circulares, lineamientos, criterios, metodologías, reglas, manuales, normas mexicanas y normas oficiales mexicanas, o cualquier otro de naturaleza análoga que expidan las dependencias y organismos descentralizados de la administración pública federal. En otras palabras, los actos administrativos de carácter general son todas aquellas disposiciones emitidas por un ente integrante de la administración pública federal que tienen efectos generales, abstractos y permanentes sobre aquel sector poblacional que se coloca en el supuesto de dicha norma jurídica. Doctrinalmente son denominados como "actos administrativos con efectos generales" (Tron y Ortíz, 2005), "disposiciones generales" (Martínez, 2014), "disposiciones generales administrativas" (Hamdan, 2017) o "disposiciones administrativas de carácter general” (Fernández, 2014). En lo particular, se opta por la propia definición semántica establecida en la LFPA.

Con base en ello, podemos concluir que las normas oficiales mexicanas son actos administrativos de carácter general, es decir, actos formalmente administrativos que son emitidos desde la administración pública, pero con un contenido materialmente legislativo. Dichas normas encuentran su sustento normativo en los artículos 3o. y 4o. de la LFPA, y en el diverso 3o., fracción XI, de la Ley Federal de Metrología y Normalización (en adelante LFMN), que las define como una regulación técnica de observancia obligatoria expedida por las dependencias competentes que establecen reglas, especificaciones, atributos, directrices, características o prescripciones aplicables a un producto, proceso, instalación, sistema, actividad, servicio o método de producción u operación, así como aquellas relativas a terminología, simbología, embalaje, marcado o etiquetado y las que se refieran a su cumplimiento o aplicación.

El Pleno de la Suprema Corte de Justicia de la Nación ha establecido parámetros claros y específicos sobre el alcance de las normas oficiales mexicanas, los cuales permiten sistematizar los principios que deben ser acatados para la expedición de las mismas, como lo son: 1) seguridad jurídica; 2) reserva de ley; 3) reserva reglamentaria; 4) subordinación 
Esta revista forma parte del acervo de la Biblioteca Jurídica Virtual del Instituto de Investigaciones Jurídicas de la UNAM

jerárquica; ${ }^{1}$ 5) ceñirse a lo previsto en el contexto formal y materialmente legislativo o reglamentario que otorga la cláusula habilitante y condiciona su emisión; 6) acatar los requisitos formales para su emisión, entre los que destacan su debida fundamentación, motivación y seguir el procedimiento específico para ello2 (Controversia Constitucional 71/2009, 2013), y 7) en caso de creación o modificación debe respetarse el principio de transparencia, publicidad y participación ciudadana, establecidos por el propio legislador en la exposición de motivos de la LFMN.

Por tanto, si bien las normas oficiales mexicanas son regulaciones técnicas para la comercialización de un bien o la prestación de un servicio, al ser actos administrativos de carácter general deben respetar distintos principios y parámetros que le otorgan regularidad dentro del sistema jurídico mexicano.

\section{LA TRANSPARENCIA Y PUBLICIDAD COMO PRINCIPIOS RECTORES}

DE LAS NORMAS OFICIALES MEXICANAS

Pocas son las normas e instituciones jurídicas que reconocen la transparencia y publicidad como un criterio necesario para la creación de una disposición de carácter general, desde antes de la reforma constitucional en la materia del 20 de julio de 2007, por lo que resulta relevante considerar que, desde 1992, la LFMN, en su exposición de motivos, otorgó un papel fundamental a dichos principios para la emisión de normas oficiales mexicanas bajo los siguientes parámetros:

1) El legislador consideró pertinente establecer un procedimiento uniforme y transparente que debía ser respetado por las dependencias para la emisión de esas normas.

2) Se estableció como requisito fundamental la participación tanto de las dependencias afectadas con la nueva normatividad como por el sector al que se dirige la norma.

1 Cobra relevancia la tesis I. lo.(I Región) 7 A, emitida por el Primer Tribunal Colegiado de Circuito del Centro Auxiliar de la Primera Región del rubro y texto siguientes: "ACTOS administrativos generales. Deben sujetarse a los principios de reserva de ley y de SUBORDINACIÓN JERÁRQUICA".

2 Debe recordarse que, en términos del artículo 4o. de la Ley Federal de Procedimiento Contencioso Administrativo, las normas oficiales mexicanas son actos administrativos de carácter general y, por lo tanto, deben ceñirse a los elementos y requisitos de todo acto administrativo, entre los que destacan los previstos en el artículo 3o., fracciones I, III, V y VII, en relación con el diverso 6o. de la ley en comento. 
Esta revista forma parte del acervo de la Biblioteca Jurídica Virtual del Instituto de Investigaciones Jurídicas de la UNAM

3) Se enfatizó en la obligación de publicar los proyectos en el Diario Oficial de la Federación para recibir comentarios públicos.

4) El legislador concluyó que respetar dicho procedimiento garantizaba la transparencia, publicidad y participación ciudadana, además de generar una legitimidad y reconocimiento social a la norma emitida.

Para Fuenmayor (2004), dichas características en el actuar de cualquier autoridad constituyen la materialización de una verdadera democratización del ejercicio del poder que reflejan probidad en la toma de decisiones y permiten ejercer el derecho de acceso a la información.

Ahora bien, en el plano regulatorio específico, el proceso de creación y modificación de las normas oficiales mexicanas se encuentra establecido en los artículos 43, 44, 45, 46, 47, 50, 51 de la LFMN (SCJN, 2013), el cual puede sintetizarse en los siguientes puntos: 1) elaboración del anteproyecto; 2) consideraciones del Comité Consultivo Nacional de Normalización; 3) manifestación de impacto regulatorio emitido por la Comisión Federal de Mejora Regulatoria; 4) presentación del anteproyecto ante el Comité Consultivo Nacional de Normalización; 5) respuesta a comentarios; 6) publicación de anteproyecto en el Diario Oficial de la Federación y comentarios de particulares; 7) análisis de comentarios; 8) publicación de respuestas en el Diario Oficial de la Federación, y 9) publicación de la norma oficial mexicana en el Diario Oficial de la Federación.

En ese orden de ideas, el no transparentar los procesos de creación y modificación de actos administrativos de carácter general que constituyen actos materialmente legislativos implica, en palabras de Béjar (2018), dejar en la opacidad la etapa predecisional del proceso y la imposibilidad de realizar manifestaciones sobre normas que pueden afectar a determinados grupos de la sociedad.

Cabe destacar que el único supuesto de excepción para no seguir el procedimiento ordinario de creación o modificación de normas oficiales mexicanas ordinarias (diferenciándolas de las normas de emergencia en las cuales no se encuentra la NOM en análisis), se encuentra establecido en el artículo 51 de la LFMN, el cual dicta que no será necesario respetar los principios de transparencia y publicidad cuando no subsistan las causas que motivaron la expedición de una NOM, precisándose que tal excepción no se surtirá cuando se pretendan crear nuevos requisitos o procedimientos, o bien incorporar especificaciones más estrictas, en cuyo caso deberá seguirse el procedimiento arriba descrito. 
Esta revista forma parte del acervo de la Biblioteca Jurídica Virtual del Instituto de Investigaciones Jurídicas de la UNAM

\section{LA NOM-046-SSA2-2005 y SU PROCESO DE MODIFICACIÓN EXTRAORDINARIO}

La "NOM-046-SSA2-2005. Violencia familiar, sexual y contra las mujeres. Criterios para la prevención y atención” tiene un devenir histórico que inicia en 2000. A partir de esa fecha, y hasta marzo de 2016, ha sido modificada en dos ocasiones, tanto en su proceso de creación como en su primera modificación, respetándose las formalidades establecidas por la LFMN. No obstante, el 24 de marzo de 2016 fue modificada por segunda ocasión, omi-

- tiendo el proceso ordinario previsto por dicha ley y afectando los principios - de transparencia, publicidad y participación ciudadana.

Dicha modificación se justificó en una mera "homologación" de conceptos con la Ley General de Víctimas para sustituir el concepto de "aborto" por el de "interrupción voluntaria del embarazo", y estableció, como fundamento para evadir un proceso transparente y democrático, una interpretación laxa del artículo 51 de la LFMN, alegando que no se creaban nuevos requisitos o procedimientos. Sin embargo, la redacción vigente modificó sustancialmente los requisitos y procedimientos para la práctica de la interrupción voluntaria del embarazo, y creó un nuevo procedimiento diferenciado en un grupo etario triplemente vulnerable: mujeres, ${ }^{3}$ víctimas de violación, ${ }^{4}$ y adolescentes ${ }^{5}$ entre los 12 y 17 años de edad. Esto se logró sin pasar por la consulta pública requerida, en la que debían participar autoridades creadas específicamente para la protección de niñas, niños y adolescentes, tales como el Sistema Nacional de Protección Integral de Niñas, Niños y Adolescentes y la Procuraduría Federal de Protección de Niñas, Niños y Adolescentes, con sus análogas en el ámbito estatal.

Los elementos fácticos que justifican la aseveración anterior pueden esquematizarse en los siguientes términos:

3 Con derechos específicamente reconocidos a través de la Ley General de Acceso a las Mujeres a una Vida Libre de Violencia, y cuya implementación fundamental corresponde a la Comisión Nacional para Prevenir y Erradicar la Violencia contra las Mujeres y al Sistema Nacional de Prevención y Erradicación de la Violencia contra las Mujeres.

4 Con los principios y derechos establecidos en la Ley General de Víctimas, cuya implementación fundamental corresponde a la Comisión Ejecutiva de Atención a Víctimas y el Sistema Nacional de Atención a Víctimas.

5 Con derechos reconocidos en la Ley General de los Derechos de Niñas, Niños y Adolescentes, y cuya implementación corresponde al Sistema Nacional de Protección de Niñas, Niños y Adolescentes y al Sistema Nacional de Desarrollo Integral de la Familia, a través de la Procuraduría Federal de Protección de Niñas, Niños y Adolescentes. 
Esta revista forma parte del acervo de la Biblioteca Jurídica Virtual del Instituto de Investigaciones Jurídicas de la UNAM

\section{Tabla 1. Comparativo de los procesos de CREación Y MODIFICACIÓN DE LA NOM-046-SSA2-2005}

\begin{tabular}{|c|c|c|c|}
\hline & $\begin{array}{l}\text { NOM-190-SSA1- } \\
\text { 1999, Prestación } \\
\text { de servicios de sa- } \\
\text { lud. Criterios pa- } \\
\text { ra la atención mé- } \\
\text { dica de la violencia } \\
\text { familiar }\end{array}$ & $\begin{array}{l}\text { NOM-046-SSA2-2005. } \\
\text { Violencia familiar, se- } \\
\text { xual y contra las muje- } \\
\text { res. Criterios para la pre- } \\
\text { vención y atención }\end{array}$ & $\begin{array}{l}\text { NOM-046-SSA2-2005. } \\
\text { Violencia familiar, se- } \\
\text { xual y contra las muje- } \\
\text { res. Criterios para la pre- } \\
\text { vención y atención }\end{array}$ \\
\hline $\begin{array}{l}\text { Fecha de publi- } \\
\text { cación en } D O F\end{array}$ & 8 de marzo de 2000 & 16 de abril de 2009 & 24 de marzo de 2016 \\
\hline $\begin{array}{l}\text { ¿Siguió forma- } \\
\text { lidades de crea- } \\
\text { ción o modifi- } \\
\text { cación? }\end{array}$ & Sí & Sí & No \\
\hline $\begin{array}{l}\text { Hubo consulta } \\
\text { pública con un } \\
\text { proyecto previo } \\
\text { de NOM }\end{array}$ & Sí & Sí & No \\
\hline $\begin{array}{l}\text { Número de en- } \\
\text { tes que intervi- } \\
\text { nieron en el pro- } \\
\text { ceso de creación } \\
\text { o modificación }\end{array}$ & $\begin{array}{l}123 \text { autoridades, } \\
\text { dependencias y or- } \\
\text { ganizaciones de la } \\
\text { sociedad civil }\end{array}$ & $\begin{array}{l}36 \text { autoridades, depen- } \\
\text { dencias y organizaciones } \\
\text { de la sociedad civil }\end{array}$ & 3 dependencias \\
\hline $\begin{array}{l}\text { Principales au- } \\
\text { toridades que } \\
\text { participaron en } \\
\text { el proceso de } \\
\text { creación o mo- } \\
\text { dificación en } \\
\text { términos de la } \\
\text { LFMN }\end{array}$ & $\begin{array}{l}\text { SSA } \\
\text { Sedena } \\
\text { SNDIF } \\
\text { IMSS } \\
\text { ISSSTE } \\
\text { Pemex } \\
\text { PGR } \\
\text { CNDH } \\
\text { PGJ del DF } \\
\text { SSA del DF } \\
\text { SDIF del DF } \\
\text { CDH del DF } \\
\text { Gobierno de Coa- } \\
\text { huila }\end{array}$ & $\begin{array}{l}\text { SSA } \\
\text { IMSS } \\
\text { ISSSTE } \\
\text { Pemex } \\
\text { Conapred } \\
\text { CNDH } \\
\text { Indesol } \\
\text { PGR } \\
\text { SSA del DF } \\
\text { CDH del DF } \\
\text { Organizaciones no gu- } \\
\text { bernamentales }\end{array}$ & $\begin{array}{l}\text { SSA } \\
\text { Subsecretaría de Pre- } \\
\text { vención y Promoción } \\
\text { de la Salud } \\
\text { Comité Consultivo Na- } \\
\text { cional de Normalización } \\
\text { Comisión Federal de } \\
\text { Mejora Regulatoria }\end{array}$ \\
\hline
\end{tabular}


Esta revista forma parte del acervo de la Biblioteca Jurídica Virtual del Instituto de Investigaciones Jurídicas de la UNAM http://www.juridicas.unam.mx/ https://biblio.juridicas.unam.mx/bjv https://revistas.juridicas.unam. $\mathrm{mx} /$

DOI: http://dx.doi.org/10.22201/iij.25940082e.2019.7.13019

\begin{tabular}{|c|c|c|c|}
\hline & $\begin{array}{l}\text { Cruz Roja Mexi- } \\
\text { cana } \\
\text { Universidades pu- } \\
\text { blicas } \\
\text { Organizaciones no } \\
\text { gubernamentales }\end{array}$ & & \\
\hline $\begin{array}{l}\text { Objetivo de la } \\
\text { NOM }\end{array}$ & $\begin{array}{l}\text { Establecer los cri- } \\
\text { terios a observar } \\
\text { en la atención mé- } \\
\text { dica y la orienta- } \\
\text { ción, que se pro- } \\
\text { porcionan a las y } \\
\text { los usuarios que se } \\
\text { encuentren invo- } \\
\text { lucrados en situa- } \\
\text { ciones de violencia } \\
\text { familiar. }\end{array}$ & $\begin{array}{l}\text { Establecer los criterios } \\
\text { a observar en la detec- } \\
\text { ción, prevención, aten- } \\
\text { ción médica y la orienta- } \\
\text { ción que se proporciona } \\
\text { a las y los usuarios de } \\
\text { los servicios de salud en } \\
\text { general, y en particular } \\
\text { a quienes se encuentren } \\
\text { involucrados en situa- } \\
\text { ciones de violencia fa- } \\
\text { miliar o sexual, así como } \\
\text { en la notificación de los } \\
\text { casos. }\end{array}$ & $\begin{array}{l}\text { Establecer los criterios } \\
\text { a observar en la detec- } \\
\text { ción, prevención, aten- } \\
\text { ción médica y la orienta- } \\
\text { ción que se proporciona } \\
\text { a las y los usuarios de } \\
\text { los servicios de salud en } \\
\text { general y en particular a } \\
\text { quienes se encuentren } \\
\text { involucrados en situa- } \\
\text { ciones de violencia fa- } \\
\text { miliar o sexual, así como } \\
\text { en la notificación de los } \\
\text { casos. }\end{array}$ \\
\hline $\begin{array}{l}\text { Numerales mo- } \\
\text { dificados }\end{array}$ & No aplica. & $\begin{array}{l}\text { Reestructuración y cam- } \\
\text { bio de denominación de } \\
\text { la NOM. }\end{array}$ & $\begin{array}{l}6.4 .2 .7,6.4 .2 .8,6.6 .1 \text { y } \\
6.7 .2 .9 .\end{array}$ \\
\hline $\begin{array}{l}\text { Justificación de } \\
\text { la modificación }\end{array}$ & No aplica. & $\begin{array}{l}\text { Solución amistosa ante } \\
\text { la Comisión Interame- } \\
\text { ricana de Derechos Hu- } \\
\text { manos al "Caso Paulina". }\end{array}$ & $\begin{array}{l}\text { "Homologar" conceptos } \\
\text { con la Ley General de } \\
\text { Víctimas. }\end{array}$ \\
\hline $\begin{array}{l}\text { Regulación del } \\
\text { aborto médico } \\
\text { o interrupción } \\
\text { voluntaria del } \\
\text { embarazo. }\end{array}$ & $\begin{array}{l}\text { No regulaba el } \\
\text { aborto médico. }\end{array}$ & $\begin{array}{l}\text { Regula la píldora del día } \\
\text { siguiente y el aborto mé- } \\
\text { dico como consecuen- } \\
\text { cia de una violación. }\end{array}$ & $\begin{array}{l}\text { Regula la interrupción } \\
\text { voluntaria del embarazo } \\
\text { en caso de violación. }\end{array}$ \\
\hline $\begin{array}{l}\text { Requisitos para } \\
\text { practicar el } \\
\text { aborto/IVE }\end{array}$ & $\begin{array}{l}\text { 1) No lo regulaba. } \\
\text { 2) En caso de inca- } \\
\text { pacidad médica o } \\
\text { legal se daba vista } \\
\text { al Ministerio Pú- } \\
\text { blico. }\end{array}$ & $\begin{array}{l}\text { 1) Denuncia previa del } \\
\text { delito ante el Ministerio } \\
\text { Público. } \\
\text { 2) Menores de edad } \\
\text { acompañadas de padre, } \\
\text { madre o tutor. }\end{array}$ & $\begin{array}{l}\text { 1) No requiere denun- } \\
\text { cia previa ante el Mi- } \\
\text { nisterio Público. } \\
\text { 2) Requiere un escrito } \\
\text { bajo protesta de decir } \\
\text { verdad de que la niña o } \\
\text { adolescente fue víctima } \\
\text { de violación. } \\
\text { 3) Niñas de hasta } 12 \\
\text { años deben ir acompa- } \\
\text { ñadas de padres, tutores } \\
\text { o representantes legales }\end{array}$ \\
\hline
\end{tabular}


Esta revista forma parte del acervo de la Biblioteca Jurídica Virtual del Instituto de Investigaciones Jurídicas de la UNAM http://www.juridicas.unam.mx/ https://biblio.juridicas.unam.mx/bjv

DOI: http://dx.doi.org/10.22201/iij.25940082e.2019.7.13019

EL ACCESO A LA INFORMACIÓN PÚBLICA EN ACTOS ADMINISTRATIVOS...

\begin{tabular}{|c|c|c|c|}
\hline & & & $\begin{array}{l}\text { 4) Niñas mayores de } 12 \\
\text { años en adelante pue- } \\
\text { den acudir sin compañía } \\
\text { de sus padres, tutores o } \\
\text { representantes legales. }\end{array}$ \\
\hline $\begin{array}{l}\text { Coordinación } \\
\text { con otras au- } \\
\text { toridades para } \\
\text { dar una protec- } \\
\text { ción integral a } \\
\text { niñas y adoles- } \\
\text { centes y perse- } \\
\text { guir el delito }\end{array}$ & Ministerio Público & Ministerio Público & $\begin{array}{l}\text { Ninguna autoridad. } \\
\text { Se da aviso posterior al } \\
\text { Ministerio Público. } \\
\text { Se informa a la adoles- } \\
\text { cente que puede acudir } \\
\text { a la Comisión Ejecuti- } \\
\text { va de Víctimas corres- } \\
\text { pondiente. } \\
\text { No se da vista a las pro- } \\
\text { curadurías de protec- } \\
\text { ción de niñas, niños y } \\
\text { adolescentes. }\end{array}$ \\
\hline $\begin{array}{l}\text { Fundamento le- } \\
\text { gal de la crea- } \\
\text { ción o modifica- } \\
\text { ción }\end{array}$ & $\begin{array}{l}\text { a) } 39 \text { de la Ley Or- } \\
\text { gánica de la Admi- } \\
\text { nistración Pública } \\
\text { Federal. } \\
\text { b) 3o., fracciones } \\
\text { III y XVIII, 5o., } \\
\text { 6o., 13, apartado A, } \\
\text { 169, } 171 \text { y demás } \\
\text { relativos de la Ley } \\
\text { General de Salud. }\end{array}$ & $\begin{array}{l}\text { a) } 39 \text { de la Ley Orgáni- } \\
\text { ca de la Administración } \\
\text { Pública Federal. } \\
\text { b) 4o. de la Ley Federal } \\
\text { de Procedimiento Ad- } \\
\text { ministrativo. }\end{array}$ & $\begin{array}{l}\text { a) } 39 \text { de la Ley Orgáni- } \\
\text { ca de la Administración } \\
\text { Pública Federal. } \\
\text { b) 4o. de la Ley Federal } \\
\text { de Procedimiento Ad- } \\
\text { ministrativo. }\end{array}$ \\
\hline
\end{tabular}

6 Dicha regulación por sí misma constituye una violación sistemática al derecho internacional de los derechos humanos especializados en niñas, niños y adolescentes, así como a la propia norma constitucional y a la Ley General de los Derechos de Niñas, Niños y Adolescentes, pues bajo ningún parámetro superior a un reglamento se discrimina a las adolescentes pertenecientes al grupo etario entre los 12 y 17 años, respecto a niñas menores de esa edad. También permite desconocer las obligaciones y derechos de la patria potestad; la necesidad de dar vista a las autoridades especializadas, como lo son las procuradurías de protección de niñas, niños y adolescentes, y generar un plan de protección integral que permita la restitución de derechos, entre otras circunstancias, así como violaciones sistemáticas al interés superior de la niñez y a los principios de transversalidad y corresponsabilidad. Por lo antes descrito, resulta evidente que la modificación en análisis no fue una mera "homologación" de conceptos. 
Esta revista forma parte del acervo de la Biblioteca Jurídica Virtual del Instituto de Investigaciones Jurídicas de la UNAM

110

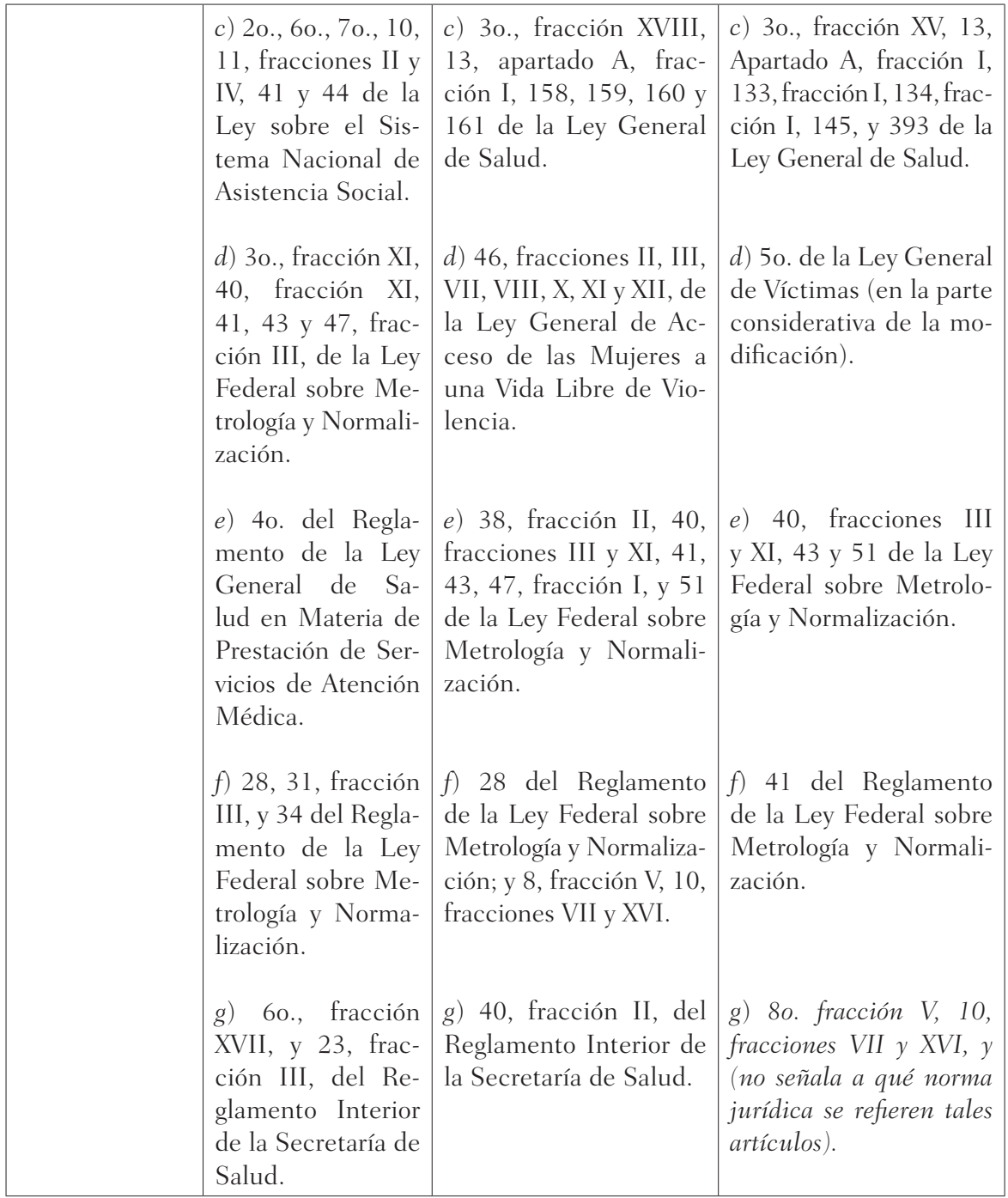

FuENTE: elaboración propia con base en la legislación antes referida.

Del análisis de los datos antes precisados puede advertirse, prima facie, que los cambios a la NOM-046-SSA2-2005 no respetaron el proceso de modificación ordinario previsto por la LFMN, y, con ello, se genera una violación a los principios de transparencia, publicidad y participación ciudadana.

En ese sentido, mediante solicitud de transparencia, con número de folio 0001200389817, se requirió acceso a la Secretaría de Salud al 
Esta revista forma parte del acervo de la Biblioteca Jurídica Virtual del Instituto de Investigaciones Jurídicas de la UNAM

expediente administrativo mediante el cual se modificó la NOM-046SSA2-2005. Al dar respuesta a dicha solicitud, el sujeto obligado reservó la información en términos del artículo 113, fracción XI, de la Ley General de Transparencia y Acceso a la Información Pública Gubernamental, con su correlativo en el diverso 110, fracción X, de la Ley Federal de la materia, manifestando la existencia de tres controversias constitucionales pendientes de resolución ante la Suprema Corte de Justicia de la Nación, y señaló como elementos justificados de su prueba del daño, la posibilidad de afectar el juicio de los ministros de dicha corte, así como trastocar el quehacer administrativo de dicha Secretaría.

Con la finalidad de contar con parámetros objetivos sobre los alcances de la causal de reserva sobre la información solicitada, se interpuso el recurso (RRA 591/18, 2018) ante el INAI.

\section{LA interpretación del artículo 113, Fracción XI DE LA LEY General de Transparencia y acceso a la Información Pública EN RELACIÓN CON LOS PROCESOS DE MODIFICACIÓN DE NORMAS OFICIALES MEXICANAS}

Los artículos 104 y 113, fracción XI, de la LGTAIP, en relación con los diversos 97, 110, fracción XI, y 111 de la LFTAIP, establecen que puede clasificarse como información reservada aquella que vulnere la conducción de expedientes judiciales o de procedimientos administrativos seguidos en forma de juicio en tanto no hayan causado estado, y para lo cual debe acreditarse la prueba del daño.

Para la interpretación y aplicación de dicha causal de reserva debe considerarse a la par los Lineamientos Generales en Materia de Clasificación y Desclasificación de la Información, así como para la Elaboración de Versiones Públicas emitidas por el Consejo Nacional del Sistema Nacional de Transparencia, Acceso a la Información Pública y Protección de Datos Personales y, de manera específica, el lineamiento trigésimo en el que se establece que deben acreditarse dos elementos fundamentales: 1) la existencia de un juicio o procedimiento administrativo materialmente jurisdiccional que se encuentre en trámite, y 2) que la información solicitada se refiera a actuaciones, diligencias o constancias propias del procedimiento.

En ese sentido, la cuestión jurídica a dilucidar consiste en analizar si el proceso de modificación de una norma oficial mexicana, caracterizado por los principios de transparencia, publicidad y participación ciudadana, puede reservarse por la existencia de controversias constitucionales pen- 
Esta revista forma parte del acervo de la Biblioteca Jurídica Virtual del Instituto de Investigaciones Jurídicas de la UNAM

dientes de resolución ante la SCJN. Así, el recurso de revisión del INAI (RRA 591/18, 2018) realizó una labor interpretativa sobre los alcances del artículo 113, fracción XI, de la LGTAIP, y 110, fracción XI, de la LFTAIP, así como las constancias que integran el proceso de modificación de la NOM-046-SSA2-2005 en los siguientes términos:

1) Por lo que hace al primer requisito, referente a la existencia de juicios pendientes de resolución, el INAI concluyó que se encontraba debidamente actualizado con la existencia de las controversias constitucionales 45/2016, 53/2016 y 54/2016, pendientes de resolución ante la SCJN.

2) Referente al segundo requisito, consistente en que la información solicitada se refiera a actuaciones, diligencias o constancias propias del procedimiento, el INAI concluyó que si bien existe una vinculación entre la información solicitada y las controversias constitucionales, las documentales que integran el proceso de modificación no corresponden con instrumentos que hubieran sido generados a partir del inicio de las controversias constitucionales, pues se trata de documentos de trabajo realizados en torno a un proyecto de modificación, por lo cual no se actualizaba la causal de reserva hecha valer por el sujeto obligado.

3) En relación con la prueba del daño, el INAI consideró que no existe un riesgo real, demostrable ni identificable que afecte el interés público, puesto que la teleología de las controversias constitucionales consiste en determinar si existe o no invasión a esferas competenciales en cuanto al contenido mismo de la norma impugnada, y no sobre su proceso de modificación.

4) Agregó, además, que la divulgación de dicho proceso no puede considerarse como suficiente para afectar el juicio de los ministros de la SCJN, pues ello implicaría dudar de la libertad para resolver del máximo tribunal constitucional del país, el cual no resuelve atendiendo a opiniones o factores externos, sino conforme a los derechos o deberes establecidos en la Constitución.

En tales circunstancias, instruyó al sujeto obligado a entregar la información relacionada con el proceso de modificación de la NOM-046SSA2-2005, sin que a la fecha exista un cumplimiento a esa resolución por parte del sujeto obligado, lo que evidentemente afecta el derecho de acceso a la información. 
Esta revista forma parte del acervo de la Biblioteca Jurídica Virtual del Instituto de Investigaciones Jurídicas de la UNAM

\section{Consideraciones finales}

Las normas oficiales mexicanas son actos administrativos de carácter general que, por mandato del legislador federal, establecido desde 1992, deben acatar los procesos de creación o modificación previstos por la LFMN, en los que la transparencia, la publicidad y la consulta pública se erigen como principios fundamentales para garantizar una gestión transparente en las actividades gubernamentales, legitimar las decisiones, reflejar la probidad de las decisiones tomadas y la responsabilidad frente a las mismas en su emisión.

Por ello, el proceso de creación y modificación de las NOM, acorde con lo establecido en la LFMN, se erige como un antecedente histórico vigente de la aplicación de los principios de transparencia, publicidad y consulta pública, mucho antes de que el Constituyente Permanente realizará la reforma constitucional en la materia en 2007.

Sin embargo, la modificación a la NOM-046-SSA2-2005, publicada el 24 de marzo de 2016 en el Diario Oficial de la Federación, no se sujetó a las disposiciones previstas por la LFMN para realizarla, y conculcó los principios de transparencia, publicidad y consulta pública que hubieren otorgado legitimación a la regulación emitida. Además, al solicitar el acceso a los documentos que integran el expediente de modificación, el sujeto obligado reservó la información al considerar que la existencia de tres controversias constitucionales pendientes de resolución ante la SCJN eran razón suficiente para actualizar la causal de reserva prevista en los artículos 113, fracción XI, de la LGTAIP, y 110, fracción XI, de la LFTAIP.

Finalmente, debe destacarse la labor del INAI que, como organismo garante, a través del recurso de revisión 591/18 (2018), ha refrendado los principios de publicidad y transparencia en los procesos de creación y modificación de las NOM, al concluir que dichos procesos no pueden clasificarse como reservados ante la existencia de controversias constitucionales.

\section{Fuentes de INFORMACIÓN}

Aristóteles, 1988, Analíticos primeros, Madrid, Gredos.

Aristóteles, Analíticos segundos, Madrid, Gredos.

BÉJAR, Luisa, 2018, "¿Qué tan transparente es el proceso legislativo en México? Una propuesta de estudio desde el análisis de políticas públicas”, en Luna Pla, Issa y Puente, Khemvirg (coords.), Trasparencia legislativa 
Esta revista forma parte del acervo de la Biblioteca Jurídica Virtual del Instituto de Investigaciones Jurídicas de la UNAM

y parlamento abierto: análisis institucional y contextual, México, Instituto de Investigaciones Jurídicas.

Cicerón, 2007, Tratado de la República, México, Porrúa.

Dahesa, Gerardo, 2006, Etimología jurídica, México, Suprema Corte de Justicia de la Nación.

Fernández, José, 2014, Derecho administrativo y administración pública,

México, Porrúa.

Fuenmayor, Alejandro, 2004, El derecho de acceso de los ciudadanos a la información pública. Análisis jurídico y recomendaciones para una propuesta - de ley modelo sobre el derecho de acceso de los ciudadanos a la información - pública, Costa Rica, UNESCO.

Hamdan, Fauzi, 2017, Derecho administrativo, México, Suprema Corte de Justicia de la Nación, vol. 3.

Martínez, Rafael, 2014, Derecho administrativo, ler. curso, México, Oxford. Pérez, Alberto, 2014, Teoría general del acto administrativo, México, Porrúa. Tron, Jean у Оrтíz, Gabriel, 2005, La mulidad de los actos administrativos, México, Porrúa.

\section{Marco jurídico}

INAI, 2018, RRA 591/18, 591/18.

Ley Federal de Metrología y Normalización (LFMN), disponible en: https:// www.gob.mx/cms/uploads/attachment/file/107522/LEYFEDERALSOBREMETROLOGIAYNORMALIZACION.pdf.

Ley Federal de Procedimiento Administrativo (LFPA), disponible en: http:// www.diputados.gob.mx/LeyesBiblio/pdf/112_180518.pdf.

Ley Federal de Transparencia y Acceso a la Información Pública (LFTAIP), disponible en: http://inicio.ifai.org.mx/LFTAIPG/LFTAIPG.pdf.

Ley General de Transparencia y Acceso a la Información Pública (LGTAIP), disponible en: http://www.dof.gob.mx/avisos/2493/SG_090516/SG_0905 16.html.

Ley General de Transparencia y Acceso a la Información Pública Gubernamental (LGTAIPG).

Ley General de Víctimas (LGV), disponible en: http://www.diputados.gob. $m x /$ LeyesBiblio/pdf/LGV_030117.pdf. 
Esta revista forma parte del acervo de la Biblioteca Jurídica Virtual del Instituto de Investigaciones Jurídicas de la UNAM

Lineamientos Generales en Materia de Clasificación y Desclasificación de la Información, así como para la Elaboración de Versiones Públicas, disponible en: http://dof.gob.mx/nota_detalle.php?codigo=5433280Efec ha=15/04/2016.

NOM-046-SSA2-2005. Violencia familiar, sexual y contra las mujeres. Criterios para la prevención y atención.

NOM-190-SSA1-1999. Prestación de servicios de salud. Criterios para la atención médica de la violencia familiar.

Suprema Corte de Justicia de la Nación (SCJN), 2013, Controversia Constitucional 71/2009.

Suprema Corte de Justicia de la Nación (SCJN), 2013, Decisiones relevantes de la Suprema Corte de Justicia de la Nación. Píldora anticonceptiva de emergencia en caso de violación, núm. 67, Ciudad de México, México. 